\title{
Association of health literacy and medication self-efficacy with medication adherence and diabetes control
}

This article was published in the following Dove Press journal:

Patient Preference and Adherence

\author{
Yen-Ming Huang' \\ Olayinka O Shiyanbola' \\ Paul D Smith² \\ 'Division of Social and Administrative \\ Sciences, School of Pharmacy, \\ University of Wisconsin-Madison, \\ Madison, WI, USA; ${ }^{2}$ Department of \\ Family Medicine and Community \\ Health, University of Wisconsin- \\ Madison, Madison, WI, USA
}

\begin{abstract}
Introduction: The exact pathway linking health literacy, self-efficacy, medication adherence, and glycemic control for type 2 diabetes remains unclear. Understanding the relationship between patient factors, medication adherence, and lower glycated hemoglobin (HbAlc) may help patients better manage their disease. This study examined the association of health literacy and medication self-efficacy with self-reported diabetes medication adherence, and the association of health literacy, medication self-efficacy, and self-reported diabetes medication adherence with $\mathrm{HbA} 1 \mathrm{c}$ of patients with type 2 diabetes.

Methods: This cross-sectional study utilized a face-to-face questionnaire at two family medicine clinics in a Midwestern state among 174 patients; subjects enrolled were at least 20 years old with diagnosed type 2 diabetes, prescribed at least one oral diabetes medicine, and understood English. Questionnaires were administered to assess the participants': health literacy, using the Newest Vital Sign six-item questionnaire (NVS); self-efficacy for medication use, using the 13-item Self-Efficacy for Appropriate Medication Use Scale; and self-report medication adherence, using the eight-item Morisky Medication Adherence Scale. HbA1c values were obtained from participants' electronic medical records. Multiple linear regressions were used to explore the association of health literacy and medication self-efficacy with both medication adherence and $\mathrm{HbA} 1 \mathrm{c}$ level after controlling for all other covariates.
\end{abstract}

Results: Self-reported health status $(\beta=0.17, p=0.015)$ and medication self-efficacy $(\beta=0.53$, $p<0.001)$ were positively associated with diabetes medication adherence. Health literacy was neither associated with diabetes medication adherence $(\beta=-0.04, p=0.586)$ nor HbA1c $(\beta=-0.06, p=0.542)$. Lower diabetes medication adherence $(\beta=-0.26, p=0.008)$ and higher number of prescribed medications $(\beta=0.28, p=0.009)$ were correlated with higher HbA1c.

Conclusion: Health literacy, as measured by the NVS, does not correlate with medication adherence or glycemic control among patients with type 2 diabetes. Interventions to improve patients' self-efficacy of medication use may improve diabetes medication adherence.

Keywords: diabetes, health literacy, medication adherence, medication self-efficacy

\section{Introduction}

Diabetes is the seventh leading cause of death in the United States and affects at least 29.1 million people. ${ }^{1,2}$ In the United States, patients with diabetes have health care expenditures 2.3 times higher than expenditures for individuals in the same population who do not have diabetes. ${ }^{3}$ Although much effort has been made to prevent and improve diabetes, the cost of diabetes care has steadily risen over the past 10 years. ${ }^{1}$

The effective management of type 2 diabetes mellitus (T2DM) integrates a multifaceted effort involving lifestyle modification and pharmacotherapy interventions;
Correspondence: Yen-Ming Huang Division of Social and Administrative Sciences, School of Pharmacy, University of Wisconsin-Madison, 777 Highland Avenue, Madison, WI 53705, USA Email huang262@wisc.edu 
however, an important factor that contributes to achieving good glycemic control is treatment with antidiabetic medications and strict medication adherence. ${ }^{4,5}$ Previous studies focusing on diabetes management have shown that suboptimal medication adherence is associated with poor glycemic control and increased risk of hospitalization and mortality. ${ }^{6}$ Non-adherence continues to be a barrier to achieving optimum health outcomes in patients with T2DM. ${ }^{7}$ Moreover, previous research has shown that patients with T2DM have one of the lowest medication adherence rates, at $31 \%{ }^{8}$

Patients with diabetes require adequate self-care skills, such as weight control, stress management, optimal exercise, and medication use, to manage their disease. ${ }^{9}$ These skills rely on the patient's abilities (eg, health literacy and self-efficacy) to obtain, process, comprehend, and follow diabetes-specific information. ${ }^{9}$ Previous reports in the literature show that health literacy and self-efficacy determine how well patients can manage medication regimens and tailor their health behaviors in the self-management of chronic diseases. ${ }^{10-12}$ Patients with diabetes and limited health literacy are likely to report less knowledge about diabetes and worse glycemic control. ${ }^{13,14}$ Furthermore, increased patient confidence in their ability to take their diabetes medications is associated with improved medication adherence and better glycemic control, as measured with glycated hemoglobin (HbA1c). ${ }^{15}$ As a result, a patient's health literacy and self-efficacy are important in successfully executing the complex recommendations related to diabetes self-care including blood glucose monitoring, interpretation of laboratory data, modification of dietary intake, and administration of medication. ${ }^{12}$

Despite the reported associations between health literacy and medication adherence as well as self-efficacy and medication adherence, the exact pathway linking health literacy, self-efficacy, medication adherence, and glycemic control remains unclear. ${ }^{10,14,16-20}$ Prior research has investigated the relationship of two or three of these four variables for diabetes management: health literacy, self-efficacy, medication adherence, and glycemic control. To our knowledge, no study has examined the relationship between all four of these variables for patients with diabetes. In addition, findings from prior diabetes studies with regard to the relationships among health literacy, self-efficacy, and health outcomes have been inconsistent. ${ }^{14,16,19}$

Until now, the major strategy to improve medication adherence and glycemic control in patients with diabetes has focused on developing readable diabetes educational materials and/or providing education about diabetes for knowledge enhancement. However, changes in self-care behaviors and health outcomes often do not follow knowledge change. ${ }^{11,21}$ Understanding the relationship between patient factors, medication adherence, and glycemic control may enhance the development of effective adherence interventions for patients with diabetes. ${ }^{17,22}$ Moreover, this may help health care providers provide patients with appropriate tailored interventions to enhance their health literacy, selfmanagement skills, and diabetes health outcomes.

This study aimed to examine 1) the association of health literacy and medication self-efficacy with self-reported diabetes medication adherence, and 2) the association of health literacy, medication self-efficacy, self-reported diabetes medication adherence with $\mathrm{HbA} 1 \mathrm{c}$ among patients with T2DM. The conceptual framework of this study is shown in the Figure S1.

\section{Methods \\ Study design}

This cross-sectional study using a questionnaire that was administered face-to-face was conducted at two family medicine clinics in a Midwestern state from March to August 2016. The Health Sciences Institutional Review Board at the University of Wisconsin-Madison approved the study procedures (2015-1284). All participants provided written informed consents in this study.

\section{Data source}

A list of potential patients was gathered from the two family medical clinics. Using an electronic medical record database, patients who met the inclusion criteria for age, T2DM, and being currently prescribed one or more oral diabetes treatment medications were identified.

\section{Sample and procedure}

A convenience sample of patients was recruited. Study participants were eligible if they were 20 years or older, diagnosed with T2DM, presently prescribed at least one daily oral diabetes medicine, and able to understand English.

Office staff approached eligible individuals on the patient list with a scheduled appointment and, if interested, they were referred to a researcher. Potential participants were provided the study information sheet; informed consent was obtained, and a face-to-face survey was administered in a private space. Participants were compensated US \$25 cash for their participation after the completion of the survey.

\section{Measurements}

\section{Demographic and other characteristics}

Sociodemographic information included age, gender, race, highest education level, health insurance, and annual 
household income. Clinical characteristics included the self-reported health status, number of medications used, number of chronic illnesses, frequency of daily diabetes medication use, duration of diabetes diagnosis, and whether the participant used insulin for diabetes control. Age, the number of medications used, the number of chronic illnesses, the frequency of daily diabetes medication use, and duration since diabetes was diagnosed were measured as continuous variables. Gender and household income were measured as dichotomous variables. Race, highest education level, and self-reported health status were measured as polytomous categorical variables.

\section{Health literacy}

Health literacy was measured using the six-item Newest Vital Sign (NVS), which tested the respondent's literacy, comprehension, application/function, evaluation, and numeracy skills. ${ }^{23,24}$ This validated measure has been used previously in studies among patients with T2DM. ${ }^{25-27}$ The NVS was administered face-to-face because the original NVS was only validated and tested using this method. ${ }^{23,24,27}$ In the NVS, an interviewer asks six questions related to information contained in a nutritional label from an ice cream container. ${ }^{28}$ The total score of the NVS ranges from 0 to 6 , with higher scores indicating better health literacy. ${ }^{23}$ Scores of less than 2 represent a high likelihood ( $\geq 50 \%)$ of limited (inadequate) literacy, 2-3 indicates the possibility of limited (marginal) literacy, and more than 3 suggests adequate literacy. ${ }^{23}$

\section{Medication self-efficacy}

Medication self-efficacy was assessed using the 13-item SelfEfficacy for Appropriate Medication Use Scale (SEAMS). ${ }^{29}$ The SEAMS is a reliable and valid self-report instrument that measures medication self-efficacy in chronic disease management and is appropriate for use in patients across a range of literacy skills. ${ }^{29}$ Patients are asked to indicate their level of confidence about taking medications correctly under a number of different circumstances. Each item is evaluated using a 3-point Likert-type scale (1 = not confident, $2=$ somewhat confident, and $3=$ very confident $).{ }^{29}$ The total score of SEAMS ranges from 13 to 39, with a higher score indicating the respondent has more confidence in adhering to their prescribed medication schedule. ${ }^{29}$

\section{Medication adherence}

Medication adherence was evaluated using the eight-item Morisky Medication Adherence Scale (MMAS-8). ${ }^{30-32}$
This self-report measure is reported to have acceptable internal consistency and has demonstrated construct validity in diabetes. ${ }^{30,33,34}$ Each item measures a specific medicationtaking behavior, and the aggregate score indicates one's inclination to adhere to his/her prescribed medication. ${ }^{17,31}$ The total score of the MMAS- 8 ranges from 0 to 8, with a higher score indicating better medication adherence. ${ }^{30,31}$ Medication adherence is grouped into three levels: MMAS- 8 scores of less than 6,6 to less than 8 , and 8 reflecting low, medium, and high medication adherence, respectively. ${ }^{30}$

\section{Diabetes control}

HbA1c was abstracted from electronic medical records using the most recent value for each participant within the previous 6 months. Lower HbA1c values represent better glycemic control, with values of $7.0 \%$ or lower recommended for patients with diabetes. ${ }^{35}$

\section{Analysis}

Frequency distributions and descriptive statistics were used to summarize the characteristics of the study sample. Bivariate correlations using Spearman's rho for ordinal and continuous variables examined univariate relationships between dependent and independent variables. Multiple linear regressions were used to explore the association of health literacy and medication self-efficacy with two dependent variables medication adherence and $\mathrm{HbA} 1 \mathrm{c}$ level - while adjusting for other covariates. All of the covariates relevant to outcome variables were chosen based on literature review, including demographics, diabetes- and health-related factors, health literacy, and medication self-efficacy. ${ }^{14}$ Medication adherence was regressed on both health literacy and medication self-efficacy to investigate the association of these three main variables after controlling all other covariates. Then, $\mathrm{HbA1c}$ was regressed on 1) health literacy and medication self-efficacy (Model 1), and 2) health literacy, medication self-efficacy, and medication adherence (Model 2) to examine the association of the four main variables after adjusting all other covariates. The value of R-squared $\left(R^{2}\right)$ coefficient was used to determine how closely the real data points approximated to the fitted regression line.

The polytomous independent variables were categorized into dichotomous variables to minimize the risk of losing statistical power. Race was categorized as white and nonwhite, and the highest education level was divided into two groups by using attainment of a high school diploma as the cutoff point. In addition, health status was divided into two groups: participants with self-report of poor or fair condition, and participants with self-report of good, very good, 
or excellent condition. All statistical analyses were conducted using SPSS version 23, with the statistical significance level at a two-sided $p<0.05$.

\section{Results}

A total of 199 patients were approached, and $174(87.4 \%)$ participants enrolled and completed the survey. Of the 25 patients who did not participate in the study, four $(16 \%)$ were in poor physical condition on the day of the survey, four $(16 \%)$ attributed their non-response to time constraints, two ( $8 \%$ ) stated inconvenience with completing the surveys, two ( $8 \%$ ) believed that the study would have no benefit because their diabetes was under good control, and $13(52 \%)$ declined the survey without giving specific reasons. The average completion time was 10 minutes. In this study, 100 of 174 (57.5\%) participants were female. Mean age was 58.7 (SD: 12.8 years, range 26-92 years). The majority were non-Hispanic white $(n=118,67.8 \%)$, with $43(24.7 \%)$ African American. Most of the participants $(n=108,62.1 \%)$ had completed at least a college degree. Participants averaged $3.9 \pm 1.8$ chronic illnesses and took $7.8 \pm 3.9$ prescription medications. Only 64 (36.8\%) participants took both insulin and oral antidiabetic agents, whereas 110 (63.2\%) participants only took oral antidiabetic agents. The mean duration of time since diabetes diagnosis was $9.6 \pm 7.1$ years, with a mean HbAlc of $7.7 \%$ (60.7 mmol/mol, SD: $1.6 \%)$. The average duration between the day of the latest HbA1c testing and the day that the participant completed the survey was $43.3 \pm 84.6$ days (Table 1$)$.

\section{Evaluation of health literacy, medication self-efficacy, and diabetes medication adherence}

The NVS, SEAMS, and MMAS- 8 yielded high reliability coefficients with Cronbach's alpha values of $0.80,0.93$, and 0.69 , respectively. The average NVS score was $3.7 \pm 2.0$. One hundred and four $(59.8 \%)$ participants had adequate health literacy; 31 (17.8\%) and 39 (22.4\%) participants had marginal and inadequate health literacy, respectively (Table 1). The mean total score of the SEAMS was 33.2 \pm 6.0 , and the mean MMAS- 8 score was $5.9 \pm 1.9$. The numbers of participants with low, medium, and high medication adherence were $71(40.8 \%), 61(35.1 \%)$, and $42(24.1 \%)$, respectively (Table 1). Most of the participants had adequate health literacy levels and high medication self-efficacy; however, less than one-fourth of the participants were adherent to their diabetes medication regimens.
Table I Descriptive statistics of the study participants $(n=174)$

\begin{tabular}{|c|c|c|}
\hline Variables & n (\%) & $\begin{array}{l}\text { Mean } \\
\text { (SD) }\end{array}$ \\
\hline Age (years) & & $58.7(12.8)$ \\
\hline \multicolumn{3}{|l|}{ Gender } \\
\hline Female & $100(57.5)$ & \\
\hline Male & $74(42.5)$ & \\
\hline \multicolumn{3}{|l|}{ Race } \\
\hline White & I I 8 (67.8) & \\
\hline Black & $43(24.7)$ & \\
\hline Hispanic & $8(4.6)$ & \\
\hline Asian & $4(2.3)$ & \\
\hline American Indian & I (0.6) & \\
\hline \multicolumn{3}{|l|}{ Education } \\
\hline Completed eighth grade or less & $4(2.3)$ & \\
\hline Some high school & I5 (8.6) & \\
\hline High school graduate or GED & $47(27.0)$ & \\
\hline Some college or technical school & $67(38.5)$ & \\
\hline College graduate & $24(13.8)$ & \\
\hline Graduate degree & $17(9.8)$ & \\
\hline Having health insurance & $174(100.0)$ & \\
\hline \multicolumn{3}{|l|}{ Annual household income } \\
\hline Less than US $\$ 20,000$ & $74(42.5)$ & \\
\hline Equal or more than US $\$ 20,000$ & $100(57.5)$ & \\
\hline Number of medications & & $7.8(3.9)$ \\
\hline Number of illnesses & & $3.9(1.8)$ \\
\hline \multicolumn{3}{|l|}{ Frequency of medication use } \\
\hline Once daily & $17(9.8)$ & \\
\hline Twice daily & 81 (46.6) & \\
\hline Three times daily & $56(32.2)$ & \\
\hline Four times daily & $20(11.5)$ & \\
\hline \multicolumn{3}{|l|}{ Insulin use } \\
\hline Yes & $64(36.8)$ & \\
\hline No & $110(63.2)$ & \\
\hline \multicolumn{3}{|l|}{ Self-rated health status } \\
\hline Poor & $12(6.9)$ & \\
\hline Fair & $6 I(35.1)$ & \\
\hline Good & $79(45.4)$ & \\
\hline Very good & $2 I(12.1)$ & \\
\hline Excellent & I $(0.6)$ & \\
\hline Duration of diabetes diagnosed (years) & & $9.6(7.1)$ \\
\hline HbAIc level (\%) ${ }^{a}$ & & $7.7(1.6)$ \\
\hline$\leq 7 \%(53.0 \mathrm{mmol} / \mathrm{mol})$ & $77(44.3)$ & \\
\hline$>7 \%(53.0 \mathrm{mmol} / \mathrm{mol})$ & $96(55.2)$ & \\
\hline Missing & I $(0.6)$ & \\
\hline Health literacy & & $3.7(2.0)$ \\
\hline Inadequate $($ score $=0-I)$ & $31(17.8)$ & \\
\hline Marginal $($ score $=2-3)$ & $39(22.4)$ & \\
\hline Adequate $($ score $=4-6)$ & $104(59.8)$ & \\
\hline Medication self-efficacy $($ score $=13-39)$ & & $33.2(6.0)$ \\
\hline Self-reported diabetes medication adherence ${ }^{b}$ & & $5.9(1.9)$ \\
\hline Low $($ score $<6)$ & 7I (40.8) & \\
\hline Medium (score 6 to $<8$ ) & $61(35.1)$ & \\
\hline High (score 8) & $42(24.1)$ & \\
\hline
\end{tabular}

Notes: ${ }^{\mathrm{T}}$ The mean HbAlc value of $7.7 \%$ is equal to $60.7 \mathrm{mmol} / \mathrm{mol}$. bUse of the OMMAS is protected by US Copyright laws. Permission for use is required. A license agreement is available from: Donald E Morisky, MMAS Research LLC 14725 NE 20th St. Bellevue WA 98007 or from dmorisky@gmail.com.

Abbreviations: GED, general equivalency development (or general equivalency diploma); SD, standard deviation. 


\section{Bivariate correlations of diabetes medication adherence, $\mathrm{HbAlc}$, and other covariates}

Bivariate correlations indicated significant associations between diabetes medication adherence and some participant factors including age, gender, race, annual household income, health status, medication self-efficacy, and $\mathrm{HbA1c}$ (Table 2).

Being male $\left(r_{s}=0.15, p<0.05\right)$ or older $\left(r_{s}=0.28, p<0.001\right)$ was associated with better diabetes medication adherence. Moreover, participants with higher annual household income $\left(r_{s}=0.24, p<0.01\right)$ or better health status $\left(r_{s}=0.29\right.$, $p<0.001$ ) were likely to be more adherent to their diabetes medications. Notably, participants with higher medication self-efficacy $\left(r_{s}=0.63, p<0.001\right)$ were more likely to report better diabetes medication adherence. However, non-white participants $\left(r_{s}=-0.24, p<0.01\right)$ were less likely to be adherent to their diabetes medication regimen.

Race, insulin use, and medication self-efficacy showed significant relationship with HbAlc (Table 2). Non-white participants $\left(r_{s}=0.15, p<0.05\right)$ had significantly higher $\mathrm{HbA} 1 \mathrm{c}$ levels. Furthermore, participants with higher HbA1c were more likely to receive insulin for T2DM treatment $\left(r_{s}=0.39, p<0.001\right)$. However, participants who reported higher diabetes medication adherence $\left(r_{s}=-0.24, p<0.01\right)$ were more likely to have lower $\mathrm{HbAlc}$ level. Health literacy did not have a significant association with either diabetes medication adherence $\left(r_{s}=0.12, p>0.05\right)$ or $\mathrm{HbA} 1 \mathrm{c}$ $\left(r_{s}=-0.06, p>0.05\right.$; Table 2).

\section{Association between health literacy, medication self-efficacy, diabetes medication adherence, and $\mathrm{HbAlc}$}

Health status $(\beta=0.17, p=0.015)$ and medication selfefficacy $(\beta=0.53, p<0.001)$ were positively associated with diabetes medication adherence after controlling for the covariates $\left(R^{2}=42.7 \%, p<0.001\right.$; Table 3$)$. However, health literacy $(\beta=-0.04, p=0.586)$ was not associated with diabetes medication adherence (Table 3 ). Of all predictors, medication self-efficacy was the strongest predictor of diabetes medication adherence.

After controlling for the other variables, diabetes medication adherence $(\beta=-0.26, p=0.008)$ had a significant inverse association with $\mathrm{HbAl}$; ; however, the number of medications used $(\beta=0.28, p=0.009)$ had a significant positive association with $\mathrm{HbA1c}\left(R^{2}=15.7 \%, p<0.01\right.$; Model 2 in Table 4). Specifically, for every one-point increase in medication adherence measured by the MMAS- 8 ,

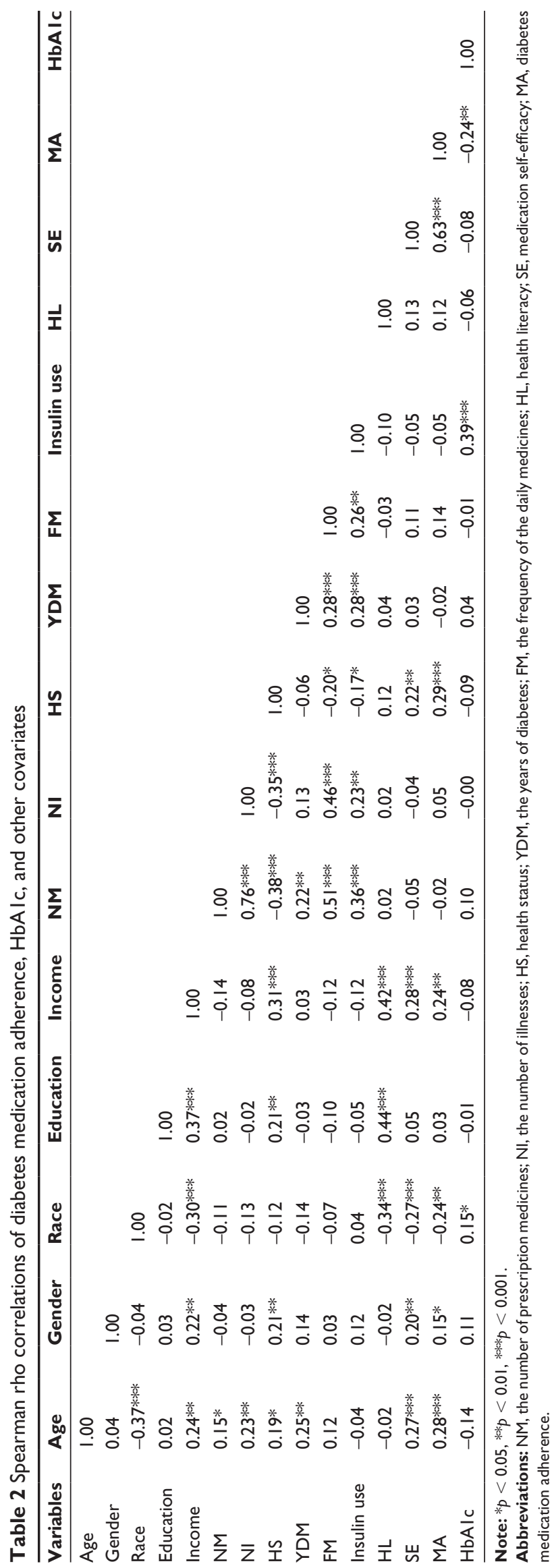


Table 3 Multiple linear regression: diabetes medication adherence regressed on demographics, diabetes- and health-related factors, health literacy, and medication self-efficacy $(n=174)$

\begin{tabular}{|c|c|c|c|c|}
\hline \multicolumn{5}{|c|}{ Dependent variable: diabetes medication adherence } \\
\hline Independent variables & B & SE & $\beta$ & $p$-value \\
\hline \multicolumn{5}{|l|}{ Demographic factors } \\
\hline Age & 0.01 & 0.01 & 0.04 & 0.581 \\
\hline Male & 0.04 & 0.24 & 0.01 & 0.858 \\
\hline Non-white ${ }^{a}$ & -0.28 & 0.29 & -0.07 & 0.330 \\
\hline Highest education degree & 0.06 & 0.27 & 0.01 & 0.837 \\
\hline \multicolumn{5}{|l|}{ more than high school level } \\
\hline Annual household income ${ }^{c}$ & 0.23 & 0.28 & 0.06 & 0.422 \\
\hline \multicolumn{5}{|c|}{ Diabetes- and health-related factors } \\
\hline Number of medications & -0.02 & 0.04 & -0.04 & 0.678 \\
\hline Number of illnesses & 0.14 & 0.09 & 0.14 & 0.123 \\
\hline Health status ${ }^{d}$ & 0.65 & 0.26 & 0.17 & 0.015 \\
\hline $\begin{array}{l}\text { Duration of diagnosed } \\
\text { diabetes (years) }\end{array}$ & -0.01 & 0.02 & -0.03 & 0.661 \\
\hline Health literacy & -0.04 & 0.07 & -0.04 & 0.586 \\
\hline Medication self-efficacy & 0.17 & 0.02 & 0.53 & $<\mathbf{0 . 0 0 1}$ \\
\hline$F$ & $10.95^{* * * *}$ & & & \\
\hline$R^{2}$ & $42.7 \%$ & & & \\
\hline
\end{tabular}

Notes: ${ }^{* * *} p<0.001$. ${ }^{\text {CCOmpared }}$ with white patients. ${ }^{\mathrm{b} C o m p a r e d}$ with those with highest education degree less than some college or technical school. cMeasured at the annual household income of US $\$ 20,000$. ${ }^{d}$ Compared with poor or fair health status reported. The values in bold font show statistical significance $(p<0.05)$.

Abbreviations: $B$, unstandardized coefficient; SE, standard error; $\beta$, standardized coefficient.

on average, the $\mathrm{HbA} 1 \mathrm{c}$ decreased by $0.23 \%$. Further, as a participant's HbA1c increased by $0.12 \%$, one additional medication would be prescribed for diabetes control. Health literacy $(\beta=-0.06, p=0.542)$ and medication self-efficacy
( $\beta=0.05, p=0.566)$ were not associated with the HbA1c level (Model 2 in Table 4).

\section{Discussion}

To our knowledge, this is the first study to examine the association of health literacy and medication self-efficacy with both medication adherence and glycemic control. Our initial finding showed that health status and medication self-efficacy were significantly associated with diabetes medication adherence, whereas health literacy was not associated with diabetes medication adherence after controlling for other demographics as well as diabetes- and health-related factors.

Our findings are consistent with prior research suggesting medication self-efficacy is a strong predictor of medication adherence, and that enhancing medication self-efficacy may be the basis for interventions to improve patients' self-care skills in the management of chronic disease. ${ }^{29,36}$ Greater medication self-efficacy is associated with better diabetes medication adherence, which is related to lower HbA1c levels. A comprehensive intervention focusing on medication self-efficacy components may be a more effective strategy to improve diabetes control than an isolated approach that simply fosters medication adherence by knowing patients' common barriers to taking medication. ${ }^{19}$ At the clinic, health care providers could use existing measures (eg, SEAMS) in 3-5 minutes to evaluate patients' self-efficacy for medication use and identify

Table 4 Multiple linear regression: HbAl c regressed on demographics, diabetes- and health-related factors, health literacy, medication self-efficacy, and diabetes medication adherence $(n=174)$

\begin{tabular}{|c|c|c|c|c|c|c|c|c|}
\hline \multirow{2}{*}{$\begin{array}{l}\text { Dependent variable: HbAlc } \\
\text { Independent variables }\end{array}$} & \multicolumn{4}{|c|}{ Model I } & \multicolumn{4}{|c|}{ Model 2} \\
\hline & B & SE & $\beta$ & $p$-value & B & SE & $\beta$ & $p$-value \\
\hline \multicolumn{9}{|l|}{ Demographic factors } \\
\hline Age & -0.02 & 0.01 & -0.17 & 0.061 & -0.02 & 0.01 & -0.16 & 0.074 \\
\hline Male & 0.41 & 0.26 & 0.12 & 0.118 & 0.42 & 0.28 & 0.13 & 0.105 \\
\hline Non-white ${ }^{a}$ & 0.28 & 0.32 & 0.08 & 0.379 & 0.22 & 0.31 & 0.06 & 0.486 \\
\hline $\begin{array}{l}\text { Highest education degree more than } \\
\text { high school level }^{b}\end{array}$ & -0.42 & 0.29 & -0.12 & 0.154 & -0.41 & 0.29 & -0.12 & 0.156 \\
\hline Annual household income ${ }^{c}$ & 0.26 & 0.31 & 0.08 & 0.403 & 0.31 & 0.30 & 0.09 & 0.309 \\
\hline \multicolumn{9}{|l|}{ Diabetes- and health-related factors } \\
\hline Number of medications & 0.12 & 0.05 & 0.29 & 0.009 & 0.12 & 0.05 & 0.28 & 0.009 \\
\hline Number of illnesses & -0.12 & 0.10 & -0.14 & 0.226 & -0.09 & 0.10 & -0.10 & 0.365 \\
\hline Health status ${ }^{d}$ & -0.02 & 0.29 & -0.01 & 0.953 & 0.13 & 0.29 & 0.04 & 0.653 \\
\hline Duration of diabetes diagnosed (years) & 0.01 & 0.02 & 0.04 & 0.590 & 0.01 & 0.02 & 0.04 & 0.644 \\
\hline Health literacy & -0.04 & 0.08 & -0.05 & 0.621 & -0.05 & 0.08 & -0.06 & 0.542 \\
\hline Medication self-efficacy & -0.02 & 0.02 & -0.08 & 0.305 & 0.02 & 0.03 & 0.05 & 0.566 \\
\hline Diabetes medication adherence & & & & & -0.23 & 0.09 & -0.26 & 0.008 \\
\hline$F$ & $2.00 *$ & & & & $2.5 I^{* *}$ & & & \\
\hline$R^{2}$ & $12.0 \%$ & & & & $15.7 \%$ & & & \\
\hline
\end{tabular}

Notes: Model I did not include diabetes medication adherence in the regression, but Model 2 included diabetes medication adherence as a covariate in the regression. ${ }^{*} p<0.05,{ }^{*} p<0.01$. ${ }^{a}$ Compared with white patients. ${ }^{b}$ Compared with those with highest education degree less than college or technical school. ${ }^{c}$ Measured at the annual household income of US $\$ 20,000$. ${ }^{d}$ Compared with poor or fair self-reported health status. The values in bold font show statistical significance ( $p<0.05$ ).

Abbreviations: $B$, unstandardized coefficient; $S E$, standard error; $\beta$, standardized coefficient. 
their barriers to taking medication. To improve medication self-efficacy in a more effective manner, health care providers may offer non-didactic group education to prompt patient interaction and help patients overcome barriers to nonadherence. ${ }^{37}$ Messaging interventions (eg, short text messages, telephone calls, or web-based feedback) help reduce diabetes distress and improve patient confidence in medication use. ${ }^{38}$ Based on the individual need of each patient, a customized video intervention may help improve patients' medication self-efficacy and reduce problems with medication use. ${ }^{39}$ As a result, improved medication adherence and better glycemic control may be achieved among patients with diabetes.

Corresponding to some previous diabetes studies, our results show no association between health literacy and diabetes medication adherence. ${ }^{18,40}$ However, Osborn et al contradict these findings as they reported higher health literacy was significantly associated with better diabetes medication adherence, although they used different measures for both health literacy (the Rapid Estimate of Adult Literacy in Medicine) and medication adherence (subscale of the Summary of Diabetes Self-Care Activities). ${ }^{28}$ It may be that health literacy, as measured by the NVS, is not directly associated with medication adherence, but exerts its impact on medication adherence through its influence on health knowledge, medication beliefs, illness perceptions, or self-efficacy. ${ }^{41,42}$ Medication adherence involves a complex set of actions that may be mediated or moderated by a wide range of patients' factors and confounders that mask any direct associations. ${ }^{18}$ Some other unobserved determinants may mediate or moderate the relationship between health literacy and medication adherence; therefore, future research should explore such relationships. ${ }^{43}$

The results of this study revealed that the number of medications used and diabetes medication adherence were significantly associated with $\mathrm{HbA} 1 \mathrm{c}$ level of patients on multiple linear regressions. It is well documented that T2DM generally worsens gradually over time and becomes more difficult to treat. ${ }^{44,45}$ Our participants had been managing their diabetes for an average of 9.6 years; therefore, it was not surprising that years of diabetes diagnosis correlated with the number of medications, the frequency of medications, and insulin use. As current diabetes medications become less effective over time, additional treatments are necessary, and the increased complexity of the medications prescribed makes adherence more difficult. This results in an inverse relationship between treatment complexity and glycemic control, and an increase in non-adherence. ${ }^{44}$ Better adherence to diabetes medication was associated with better glycemic control as for every one-point (12.5\%) increase in
MMAS-8, there was a corresponding HbA1c decrease of $0.23 \%(p=0.008)$, which is consistent with reports from previous studies on diabetes. ${ }^{44,46}$

Health literacy did not predict HbA1c, consistent with several previous studies. ${ }^{9,10,12,13,42}$ However, health literacy may act as a distant contributor influencing glycemic control via other mediators, such as correct medication use and access to medical care. ${ }^{14,20}$ Health literacy has a variety of attributes and required skills; therefore, health literacy measurement tools that only assess a few of these attributes and skills may not show an association. ${ }^{24}$

Self-efficacy was reported as an important predictor of glycemic control in previous studies. ${ }^{47-49}$ However, our study showed no significant association between medication self-efficacy and HbA1c level. One of the reasons for this discrepancy may result from different measures of self-efficacy assessment. The previous studies assessed self-efficacy using multidimensional diabetes questionnaires such as the Perceived Competence for Diabetes Scale and the Diabetes Empowerment Scale-Short Form. ${ }^{48,49}$ These diabetes scales captured several aspects of diabetes selfmanagement, including diet control, exercise adoption, blood glucose monitoring, medication taking, foot care, and smoking cessation. ${ }^{48,49}$ However, no investigator could identify which specific behavior of diabetes self-management was most affected by self-efficacy. Instead of using these multidimensional measures, we evaluated self-efficacy of patients using SEAMS, which focuses on medication use only; therefore, this narrow measurement of self-efficacy may explain the lack of association in our results.

This study has several limitations. This cross-sectional study measured all variables from a single study visit; therefore, we were unable to ascertain the persistence of medication adherence and glycemic control over time. The generalizability of these study findings beyond this patient population is unknown because our sample is not representative of all of the patients with T2DM in other care settings. Moreover, diabetes medication adherence was assessed on the basis of a self-report measure rather than by using objective measures of adherence, and it may be overestimated or non-reflective of actual medication use due to recall biases and social desirability. ${ }^{50}$

The findings from this study indicate a substantial opportunity for improving diabetes control, based on lower HbAlc, through improved diabetes medication adherence. Medication self-efficacy appears to be the strongest identified factor that influences medication use adherence. To date, enhancing diabetes-related knowledge by developing readable self-care materials has been the most frequent intervention in general practice. However, behavioral change does not always follow 
knowledge change. Based on the findings from this study, interventions to change medication self-efficacy of patients with T2DM is recommended in order to improve medication adherence.

\section{Acknowledgments}

Use of the CMMAS is protected by US Copyright laws. Permission for use is required. A license agreement is available from: Donald E Morisky, MMAS Research LLC 14725 NE 20th St. Bellevue WA 98007 or from dmorisky@, gmail.com.

\section{Disclosure}

The authors report no conflicts of interest in this work.

\section{References}

1. Centers for Disease Control and Prevention. Ten Leading Causes of Death and Injury. Available from: http://www.cdc.gov/injury/wisqars/ leadingcauses.html. Accessed April 30, 2017.

2. American Diabetes Association. Statistics About Diabetes. Available from: http://www.diabetes.org/diabetes-basics/statistics/?referrer=https:// www.google.com/. Accessed April 30, 2017.

3. American Diabetes Association. Economic costs of diabetes in the US in 2007. Diabetes Care. 2008;31(3):596-615.

4. Awodele O, Osuolale JA. Medication adherence in type 2 diabetes patients: study of patients in Alimosho General Hospital, Igando, Lagos, Nigeria. Afr Health Sci. 2015;15(2):513-522.

5. Nau DP. Recommendations for improving adherence to type 2 diabetes mellitus therapy - focus on optimizing oral and non-insulin therapies. Am J Manag Care. 2012;18(3 Suppl):S49-S54.

6. Ho PM, Rumsfeld JS, Masoudi FA, et al. Effect of medication nonadherence on hospitalization and mortality among patients with diabetes mellitus. Arch Intern Med. 2006;166(17):1836-1841.

7. Krass I, Schieback P, Dhippayom T. Adherence to diabetes medication: a systematic review. Diabet Med. 2015;32(6):725-737.

8. Donnan PT, MacDonald TM, Morris AD. Adherence to prescribed oral hypoglycaemic medication in a population of patients with Type 2 diabetes: a retrospective cohort study. Diabet Med. 2002;19(4): 279-284.

9. Yamashita T, Kart CS. Is diabetes-specific health literacy associated with diabetes-related outcomes in older adults? J Diabetes. 2011; 3(2):138-146.

10. DeWalt DA, Boone RS, Pignone MP. Literacy and its relationship with self-efficacy, trust, and participation in medical decision making. Am J Health Behav. 2007;31 Suppl 1:S27-S35.

11. Kim SH, Yu X. The mediating effect of self-efficacy on the relationship between health literacy and health status in Korean older adults: a short report. Aging Ment Health. 2010;14(7):870-873.

12. Osborn CY, Cavanaugh K, Wallston KA, Rothman RL. Self-efficacy links health literacy and numeracy to glycemic control. $J$ Health Commun. 2010;15 Suppl 2:146-158.

13. Rothman R, Malone R, Bryant B, Horlen C, DeWalt D, Pignone M. The relationship between literacy and glycemic control in a diabetes disease-management program. Diabetes Educ. 2004;30(2):263-273.

14. Bailey SC, Brega AG, Crutchfield TM, et al. Update on health literacy and diabetes. Diabetes Educ. 2014;40(5):581-604.

15. Sarkar U, Fisher L, Schillinger D. Is self-efficacy associated with diabetes self-management across race/ethnicity and health literacy? Diabetes Care. 2006;29(4):823-829.
16. Al Sayah F, Majumdar SR, Williams B, Robertson S, Johnson JA. Health literacy and health outcomes in diabetes: a systematic review. J Gen Intern Med. 2013;28(3):444-452.

17. Pignone MP, DeWalt DA. Literacy and health outcomes: is adherence the missing link? J Gen Intern Med. 2006;21(8):896-897.

18. Loke YK, Hinz I, Wang X, Salter C. Systematic review of consistency between adherence to cardiovascular or diabetes medication and health literacy in older adults. Ann Pharmacother. 2012;46(6):863-872.

19. Zhang NJ, Terry A, McHorney CA. Impact of health literacy on medication adherence: a systematic review and meta-analysis. Ann Pharmacother. 2014;48(6):741-751.

20. Paasche-Orlow MK, Wolf MS. The causal pathways linking health literacy to health outcomes. Am J Health Behav. 2007;31 Suppl 1: S19-S26.

21. Bijl JV, Poelgeest-Eeltink AV, Shortridge-Baggett L. The psychometric properties of the diabetes management self-efficacy scale for patients with type 2 diabetes mellitus. J Adv Nurs. 1999;30(2):352-359.

22. Abubakari AR, Cousins R, Thomas C, Sharma D, Naderali EK. Sociodemographic and clinical predictors of self-management among people with poorly controlled type 1 and type 2 diabetes: the role of illness perceptions and self-efficacy. J Diabetes Res. 2016;2016:6708164.

23. Weiss BD, Mays MZ, Martz W, et al. Quick assessment of literacy in primary care: the newest vital sign. Ann Fam Med. 2005;3(6):514-522.

24. Haun JN, Valerio MA, McCormack LA, Sørensen K, Paasche-Orlow MK. Health literacy measurement: an inventory and descriptive summary of 51 instruments. $J$ Health Commun. 2014;19 Suppl 2:302-333.

25. Kirk JK, Grzywacz JG, Arcury TA, et al. Performance of health literacy tests among older adults with diabetes. J Gen Intern Med. 2012; 27(5):534-540.

26. Miser WF, Jeppesen KM, Wallace LS. Clinical utility of a brief screen for health literacy and numeracy among adults with diabetes mellitus. Fam Med. 2013;45(6):417-423.

27. Shealy KM, Threatt TB. Utilization of the Newest Vital Sign (NVS) in practice in the United States. Health Commun. 2016;31(6):679-687.

28. Osborn CY, Cavanaugh K, Wallston KA, et al. Health literacy explains racial disparities in diabetes medication adherence. J Health Commun. 2011;16 Suppl 3:268-278.

29. Risser J, Jacobson TA, Kripalani S. Development and psychometric evaluation of the Self-Efficacy for Appropriate Medication use Scale (SEAMS) in low-literacy patients with chronic disease. J Nurs Meas. 2007;15(3):203-219.

30. Morisky DE, Ang A, Krousel-Wood M, Ward HJ. Predictive validity of a medication adherence measure in an outpatient setting. $J$ Clin Hypertens (Greenwich). 2008;10(5):348-354.

31. Krousel-Wood M, Islam T, Webber LS, Re RN, Morisky DE, Muntner P. New medication adherence scale versus pharmacy fill rates in seniors with hypertension. Am J Manag Care. 2009;15(1):59-66.

32. Morisky DE, DiMatteo MR. Improving the measurement of selfreported medication nonadherence: response to authors. $J$ Clin Epidemiol. 2011;64(3):255-257; discussion 258-263.

33. Al-Qazaz H, Hassali MA, Shafie AA, Sulaiman SA, Sundram S, Morisky DE. The eight-item Morisky Medication Adherence Scale MMAS: translation and validation of the Malaysian version. Diabetes Res Clin Pract. 2010;90(2):216-221.

34. Sakthong P, Chabunthom R, Charoenvisuthiwongs R. Psychometric properties of the Thai version of the 8-item Morisky Medication Adherence Scale in patients with type 2 diabetes. Ann Pharmacother. 2009;43(5):950-957.

35. Inzucchi SE, Bergenstal RM, Buse JB, et al. Management of hyperglycemia in type 2 diabetes, 2015: a patient-centered approach: update to a position statement of the American Diabetes Association and the European Association for the Study of Diabetes. Diabetes Care. 2015; 38(1):140-149.

36. Burke LE, Dunbar-Jacob JM, Hill MN. Compliance with cardiovascular disease prevention strategies: a review of the research. Ann Behav Med. 1997;19(3):239-263. 
37. Sperl-Hillen J, Beaton S, Fernandes O, et al. Are benefits from diabetes self-management education sustained? Am J Manag Care. 2013; 19(2):104-112.

38. Farmer AJ, McSharry J, Rowbotham S, McGowan L, Ricci-Cabello I, French DP. Effects of interventions promoting monitoring of medication use and brief messaging on medication adherence for people with Type 2 diabetes: a systematic review of randomized trials. Diabet Med. 2016;33(5):565-579.

39. Davis SA, Carpenter D, Cummings DM, et al. Patient adoption of an internet based diabetes medication tool to improve adherence: a pilot study. Patient Educ Couns. 2017;100(1):174-178.

40. Kim S, Love F, Quistberg DA, Shea JA. Association of health literacy with self-management behavior in patients with diabetes. Diabetes Care. 2004;27(12):2980-2982.

41. Unni E, Farris KB. Determinants of different types of medication nonadherence in cholesterol lowering and asthma maintenance medications: a theoretical approach. Patient Educ Couns. 2011;83(3):382-390.

42. Bains SS, Egede LE. Associations between health literacy, diabetes knowledge, self-care behaviors, and glycemic control in a low income population with type 2 diabetes. Diabetes Technol Ther. 2011;13(3):335-341.

43. Tunceli K, Zhao C, Davies MJ, et al. Factors associated with adherence to oral antihyperglycemic monotherapy in patients with type 2 diabetes. Patient Prefer Adherence. 2015;9:191-197.
44. Lawrence DB, Ragucci KR, Long LB, Parris BS, Helfer LA. Relationship of oral antihyperglycemic (sulfonylurea or metformin) medication adherence and hemoglobin A1c goal attainment for HMO patients enrolled in a diabetes disease management program. J Manag Care Pharm. 2006;12(6):466-471.

45. Odegard PS, Capoccia K. Medication taking and diabetes: a systematic review of the literature. Diabetes Educ. 2007;33(6):1014-1029; discussion 1030-1031.

46. Cramer JA, Benedict A, Muszbek N, Keskinaslan A, Khan ZM. The significance of compliance and persistence in the treatment of diabetes, hypertension and dyslipidaemia: a review. Int J Clin Pract. 2008; 62(1):76-87.

47. Wallston KA, Rothman RL, Cherrington A. Psychometric properties of the Perceived Diabetes Self-Management Scale (PDSMS). J Behav Med. 2007;30(5):395-401.

48. Williams GC, Freedman ZR, Deci EL. Supporting autonomy to motivate patients with diabetes for glucose control. Diabetes Care. 1998; 21(10):1644-1651.

49. Iannotti RJ, Schneider S, Nansel TR, et al. Self-efficacy, outcome expectations, and diabetes self-management in adolescents with type 1 diabetes. J Dev Behav Pediatr. 2006;27(2):98-105.

50. Lam WY, Fresco P. Medication adherence measures: an overview. Biomed Res Int. 2015;2015:217047. 


\section{Supplementary material}

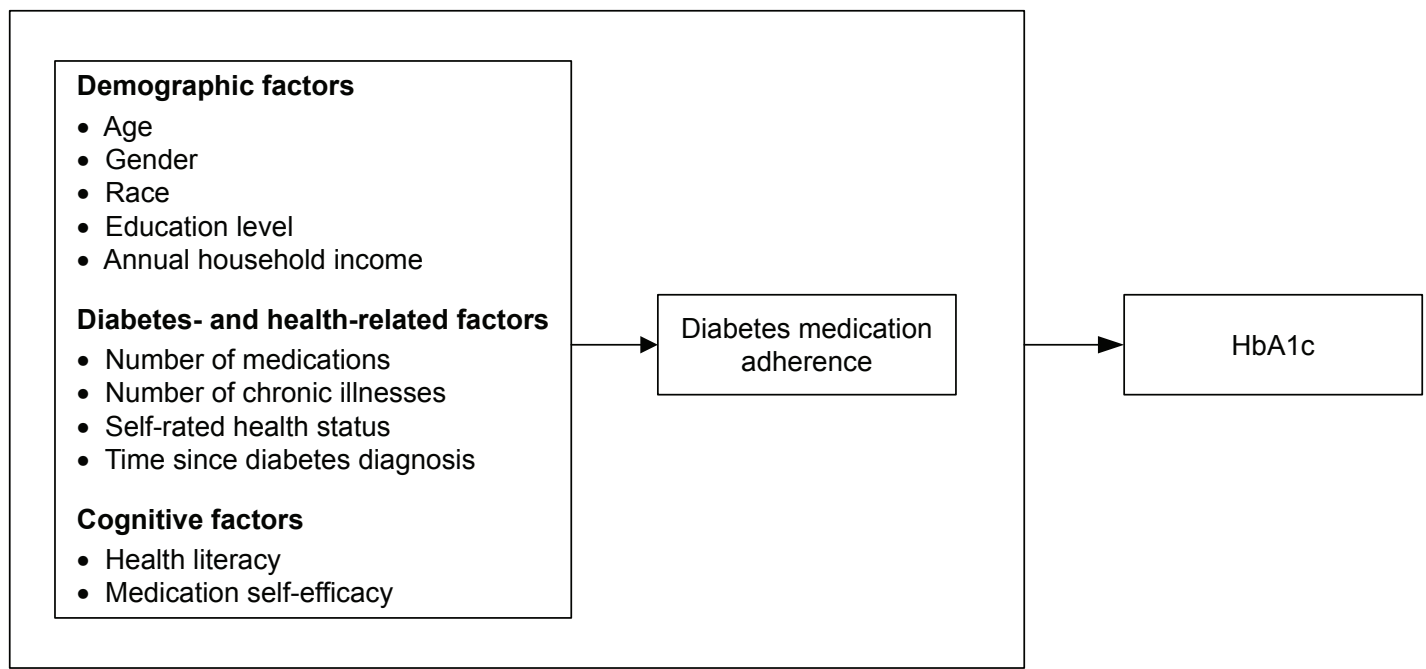

Figure SI Conceptual framework of the association of health literacy, medication self-efficacy, diabetes medication adherence, HbAIc, and the covariates based on the literature review.

\section{Publish your work in this journal}

Patient Preference and Adherence is an international, peer-reviewed, open access journal that focuses on the growing importance of patient preference and adherence throughout the therapeutic continuum. Patient satisfaction, acceptability, quality of life, compliance, persistence and their role in developing new therapeutic modalities and compounds to optimize clinical outcomes for existing disease states are major areas of interest for the journal. This journal has been accepted for indexing on PubMed Central. The manuscript management system is completely online and includes a very quick and fair peer-review system, which is all easy to use. Visit http://www dovepress.com/testimonials.php to read real quotes from published authors.

Submit your manuscript here: http://www.dovepress.com/patient-preference-and-adherence-journal 